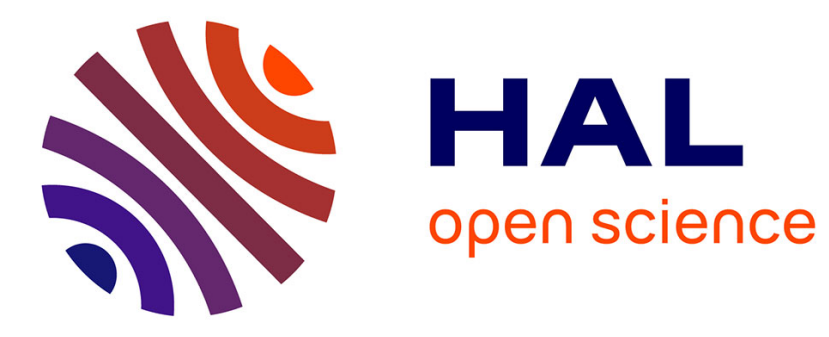

\title{
Probabilistic downscaling of GCM scenarios over southern India
}

\author{
Nicolas Vigaud, M. Vrac, Yvan Caballero
}

\section{To cite this version:}

Nicolas Vigaud, M. Vrac, Yvan Caballero. Probabilistic downscaling of GCM scenarios over southern India. International Journal of Climatology, 2013, 33 (5), pp.1248-1263. 10.1002/joc.3509 . hal02986860

\section{HAL Id: hal-02986860 https: / hal-brgm.archives-ouvertes.fr/hal-02986860}

Submitted on 3 Nov 2020

HAL is a multi-disciplinary open access archive for the deposit and dissemination of scientific research documents, whether they are published or not. The documents may come from teaching and research institutions in France or abroad, or from public or private research centers.
L'archive ouverte pluridisciplinaire HAL, est destinée au dépôt et à la diffusion de documents scientifiques de niveau recherche, publiés ou non, émanant des établissements d'enseignement et de recherche français ou étrangers, des laboratoires publics ou privés. 
ABSTRACT: The cumulative distribution function transform (CDF-t) is used to downscale daily precipitation and surf temperatures from a set of Global climate model (GCM) climatic projections over southern India. To deal with the annual cycle, the approach has been applied by months, allowing downscaled projections for all seasons. First, CDFvalidated over a historical period using observation from the Indian Meteorological Department (IMD). Resulting $h$ resolution fields show substantial improvements compared to original GCM outputs in terms of distribution, seasonal cy and monsoon means for arid, semi-arid and wetter regions of the subcontinent. Then, CDF-t is applied to GCM large-s fields to project rainfall and surface temperature changes for the 21st century under the IPCC SRES A2 scenario. results obtained show an increase of rainfall, mostly during the monsoon season, while winter precipitation is reduced, suggest a widespread warming especially in the winter and post-monsoon season. Copyright (c) 2012 Royal Meteorolog Society

KEY WORDS downscaling; climatic scenarios; southern India

Received 14 June 2011; Revised 22 March 2012; Accepted 3 April 2012

\section{Introduction}

Associated with fast social and economic growth locally, climate changes are likely to seriously impact India. As noted by Kundzewicz et al. (2007), southern India is already a water-stressed region. Climate changes have already been observed over the subcontinent, where increases of $0.4-0.6^{\circ} \mathrm{C}$ have occurred over the past century together with the annual mean temperature warming most pronounced during post-monsoon and winter periods (Rupa Kumar et al., 2006; Bhattacharya, 2007). In terms of precipitation, Cruz et al. (2007) have observed for the last decades that extreme summer monsoon rains increase over northwest India and the number of rainy days decrease along the east coast. While these projections are subject to large uncertainties (Paeth et al., 2008), the potential impacts on water resources in India still need to be assessed depending on their location.

Global climate models (GCMs) are nowadays the only tool at disposal to investigate future climate variability. However, GCM projections cannot be used directly for impact studies due to the coarse resolution of GCM outputs which are not suited for regional assessments (Wilby et al., 2004). Therefore, downscaling methods have been developed to go from large-scale data to local-scale data. The dynamical approach consists of using regional

\footnotetext{
* Correspondence to: N. Vigaud, Service EAU, Bureau de Recherches Géologiques et Minières (BRGM), Montpellier, France.

E-mail: nicolas.vigaud@gmail.com
}

climate models (RCMs) to resolve physical equ of atmospheric regional dynamics (Wood et al., ? RCMs are, however, domain dependant and comput ally expensive, which restricts their use for many ap tions. The statistical approach, on the other hand, re statistical relationships between large-scale GCM fe and local-scale climatic variables (such as precipitat temperature, for instance). Statistical downscaling ods (SDMs) are quite flexible and generally requir computational costs. Such advantages make them 1 ularly attractive for regional impact studies. SDN be classified into three major categories: transfer tions, weather typing and weather generators. $\operatorname{Tr}$ functions are based on direct quantitative relatio between predictand and predictors through regre like methods (Prudhomme et al., 2002). Weather approaches consist in the grouping (or clusterin atmospheric circulations in relation to local meteo ical variables (Vrac et al., 2007), while weather g tors are stochastic models simulating local-scale var based on their probability density function, whose $p$ eters depend on large-scale information (Hughes 1999; Wilks and Wilby, 1999; Vrac and Naveau, ? Worthnotingly, a common assumption to all SDMs the physical relationships underlying the statistica tionships identified over a historical period remain for the future climate scenarios to be downscaled.

Several SDMs have already been used for dow ing rainfall over India, such as relevance (Ghos 

large-scale and local-scale statistical characteristics and can be referred in this context as probabilistic downscaling methods (PDMs). The cumulative distribution function transform (CDF-t) presented in Michelangeli et al. (2009) has the advantage of directly dealing with and providing CDFs. This method is used in this paper to downscale GCM projections from the Intergovernmental Panel on Climate Change Fourth Assessment Report (IPCC AR4) in order to investigate projected changes in both rainfall and surface temperatures over southern India. The purpose of this study is to document the use of CDF-t for providing regional precipitation and surface temperature changes as derived from several medium-term GCM projections under the Special Report on Emission Scenarios (SRES published by the IPCC) A2 scenario (horizons 2040-2060). Most of the recent statistical downscaling studies of future climate scenarios over India were restrained to the monsoon season (Tripathi et al., 2006; Mujumdar and Ghosh, 2008) or to specific watersheds (Ghosh and Mujumdar, 2007; Anandhi et al., 2008, 2009). This paper aims to present results from the CDF-t probabilistic downscaling method applied not only to the June-September (JJAS) monsoon period alone but to the full annual cycle, and for a domain covering the whole of southern India. In the next section, the data used and the downscaling method are presented. Then, the CDF-t approach is validated on a historical period in Section 3, prior to applying the method to downscale future scenarios from IPCC AR4 experiments in Section seven GCMs as most reliable regarding Indian $\mathrm{r}$ rainfall based on their representation of the $\mathrm{m}$ sonal cycle in phase and amplitude. Regarding tl ability of daily standard outputs from the Prog Climate Model Diagnosis and Intercomparison (1 database, five GCMs have been retained (see However, at the time of this study MIROCM surface temperatures for the SRES A2 scenar not available from the PCMDI archives. Conse only four GCMs will be used for the downsc surface temperatures. Except for CGCM3, whic porates heat and water fluxes adjustments, the generation GCMs do not use surface flux corre maintain a stable climate in their control run details about the model components can be http://www.pcmdi.llnl.gov/ipcc/model-document

For the purpose of this study, simulated daily and surface temperatures have been considered fr historical experiments (run $20 \mathrm{~cm}^{3}$ for the 197 period) and future projections under the gre gas emission scenario A2 (run A2 for the 204 period). The A2 storyline, based on high popula regionally oriented economic growth with signifi widespread decline in fertility (Nakicenovic et al actually describes a very homogeneous world wit economic and technical changes than other scen Local-scale observations from the Indian Met ical Department (IMD) are also used in this stu daily rainfall is available from 1971 to 2005 or degree grid and surface temperatures from 1969

Table I. Climate models and their references participating in the IPCC AR4 experiments (adapted from Kripalani et al Abbreviated acronyms are used in the text to identify each GCM.

\begin{tabular}{|c|c|c|c|c|c|}
\hline No. & Originating group & Country & IPCC ID & Abbreviation & Reference \\
\hline 1 & $\begin{array}{l}\text { Canadian centre for climate } \\
\text { modelling }\end{array}$ & Canada & CGCM3.1 (t47) & CGCM3 & Flato et $a$ \\
\hline 2 & $\begin{array}{l}\text { Météo-France/Centre National } \\
\text { de Recherches Météorologiques }\end{array}$ & France & CNRM-CM3 & CNRM3 & $\begin{array}{l}\text { Salas-Me } \\
(2006)\end{array}$ \\
\hline 3 & $\begin{array}{l}\text { Max Planck Institute for } \\
\text { Meteorology }\end{array}$ & Germany & ECHAM5/MPI-OM & ECHAM5 & $\begin{array}{l}\text { Jungelaus } \\
\text { (2006) }\end{array}$ \\
\hline 4 & $\begin{array}{l}\text { Bjerknes Centre for Climate } \\
\text { Research }\end{array}$ & Norway & BCCR-BCM2.0 & BCCR2 & $\begin{array}{l}\text { Furevik } e \\
\text { (2003) }\end{array}$ \\
\hline 5 & $\begin{array}{l}\text { Centre for Climate System } \\
\text { Research (The University of } \\
\text { Tokyo) National Institute for } \\
\text { Environmental Studies and } \\
\text { Frontier Research Centre for } \\
\text { Global Change (JAMSTEC) }\end{array}$ & Japan & MIROC3.2 (medres) & MIROCMR & $\begin{array}{l}\text { K-1 Mod } \\
\text { Develope }\end{array}$ \\
\hline
\end{tabular}



The downscaling approach chosen here is the CDFt (Michelangeli et al. (2009)) which can be seen as an extension of the quantile-matching method. CDF-t offers the advantage to directly deal with and provide CDFs. In its non-parametric form it does not make any assumption on the shape or family of distribution and thus can be applied separately to both rainfall and surface temperatures in the context of this study. CDF-t has already been successfully used to downscale GCMs and reanalyse $10 \mathrm{~m}$ wind over France by Michelangeli et al. (2009).

Let $F_{h}$ stand for the CDF of observed local data at a given weather station (or IMD grid cell) over a historical time period $h, G_{h}$ the CDF of GCM outputs bilinearly interpolated at the station location for the same period, $F_{f}$ and $G_{f}$ their equivalent for the future period considered. The method is based on the assumption that there exists a transformation $T$ translating the CDF of a GCM variable (predictor) into the CDF representing the local-scale climate variable (predictand) at the given weather station, through the transformation $T:[0,1] \rightarrow$ $[0,1]$

$$
T\left(G_{h}(x)\right)=F_{h}(x)
$$

Replacing $x$ by $G_{h}^{-1}(u)$ in Equation (1) with $u \in[0,1]$ allows the following definition for the transform $T$ :

$$
T(u)=F_{h}\left(G_{h}^{-1}(u)\right)
$$

Assuming that this later relationship remains valid in the future (i.e. $F_{f}=T\left(G_{f}\right)$ ), the researched $\mathrm{CDF}$ is given by:

$$
F_{f}(x)=F_{h}\left(G_{h}^{-1}\left(G_{f}(x)\right)\right)
$$

Following Michelangeli et al. (2009), the CDF-t is then defined in two steps. First, estimates of $\left(F_{h}, G_{h}^{-1}, G_{f}\right)$ are non-parametrically modelled. Then, their combination using Equation (3) provides an estimate of $F_{f}$. Unlike the classical quantile-matching approach which projects the simulated future large-scale values on the historical CDF to compute and match quantiles, CDF-t takes into account the change in the large-scale CDF from the historical to the future period. To downscale rainfall/surface temperatures over the full annual cycle, CDF-t is applied at each grid point to multiannual chronicles consisting of daily rainfall/surface temperatures for each month of the calendar year (all January months, February months, etc.). The resulting local-scale daily chronicles of each month are evaluated regarding local observations from The resulting downscaled CDFs are evaluated at grid point against IMD data using Kolmogorov-Sn (KS) statistics providing an estimate of the max difference between downscaled and observed local (Darling, 1957). The results for both rainfall and $s$ temperatures over southern India are presented. Hor because rainfall has a discontinuity in zero, KS have also been computed after removal of days no precipitation, this analysis is further discuss Section 3.1. In addition, dedicated diagnostics are for three watersheds ranging from arid (Pandam semi-arid (Kudaliar) to wetter conditions (South $\mathrm{Gu}$ These locations are chosen to illustrate and the performance of the method for different cl environments.

\subsection{Precipitation regimes}

Figure 1 presents KS statistics between CDFs original GCMs rainfall (bi-linearly interpolated c $0.5^{\circ}$ IMD grid) as well as from downscaled GCM and IMD observed precipitation for 1986-1999 calibration of the CDF-t over the 1971-1985 p As mentioned previously, this KS test is perform each grid point; therefore, the box-plots display Figure 1 represent the spatial dispersion of the KS for the whole of the South India domain. For periods, the different GCMs downscaled rainfal are characterized by a spatial dispersion compara original GCM outputs. For the full year (top $p$ and for all GCMs, even if they stay above the of statistical significance $(0.019$ at 0.05 signif level, not plotted), KS scores are substantially imp for downscaled daily rainfall compared to raw data. Similar results are found for the monsoon $p$ Maximum KS scores computed in Figure 1 actually at the discontinuity of rainfall in zero, and the results thus show that dry days are better represen downscaled fields than in original GCM outputs compared to observation. This is consistent wit fact that dry days are generally rare in GCMs Consequently, similar KS scores have been plot Figure 2 after removal of days with no rainfall values) in all precipitation dataset. For the whole ye results are very contrasted depending on GCMs. $t$ seems to perform best in the case of ECHAN which downscaled rainfall are closer to observatio original GCM outputs. While there is no improv 



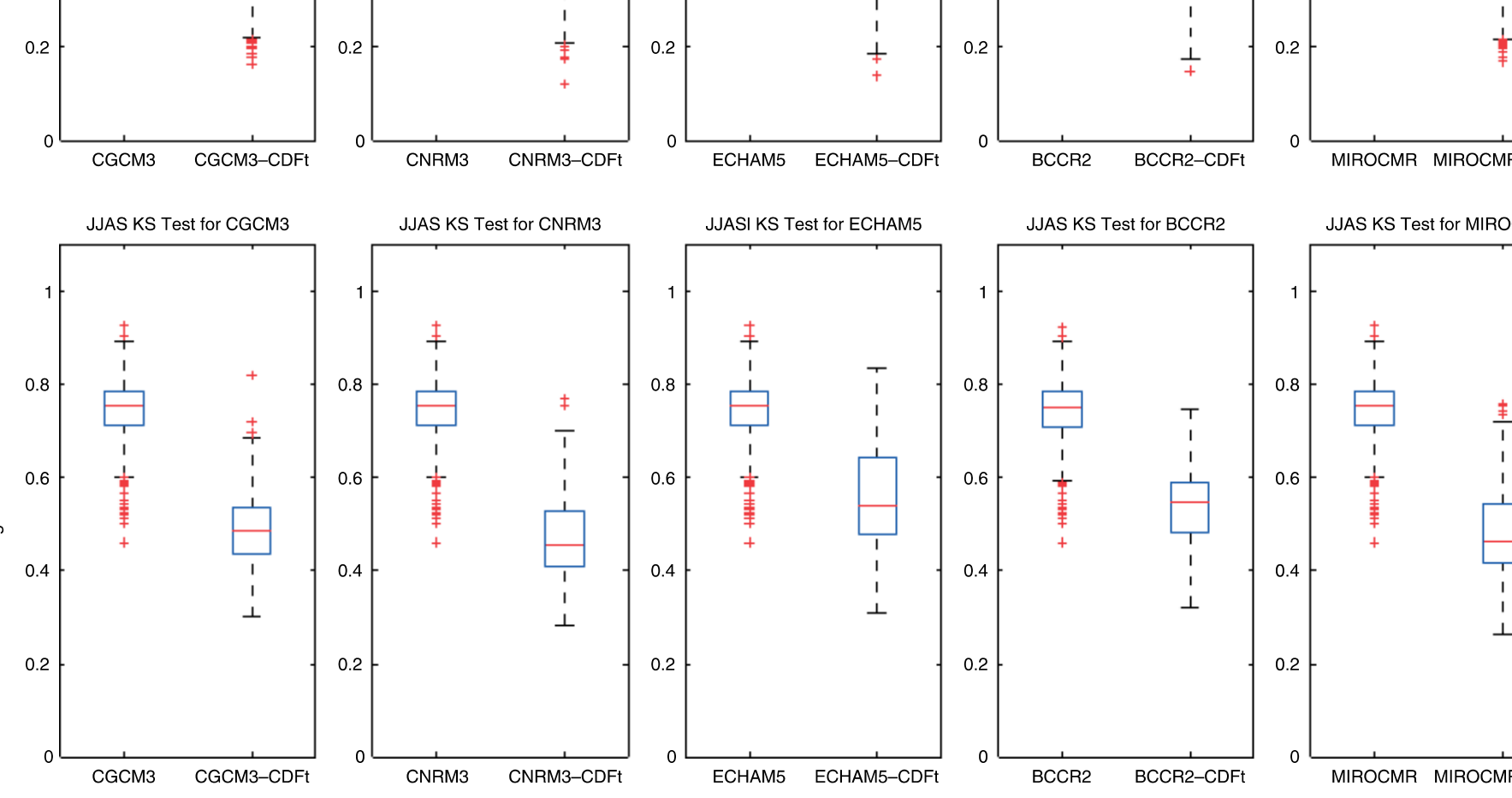

Figure 1. Kolmogorov-Smirnov statistics for original (left box-plots) and downscaled (right box-plots) GCMs rainfall when compare observation data over the 1986-1999 period for the whole of southern India, with calibration of the CDF-t over 1971-1985. Statisti for the full year and the JJAS period are presented in the top and bottom panels, respectively.

for CNRM3, the performance of the method is mitigated in the case of BCCR2, MIROCMR and CGCM3. For the JJAS period however, downscaled rainfall using CDF-t are all closer to observation than original GCMs data, witnessing of a good performance of CDF-t over the monsoon season.

In addition, downscaled GCMs daily rainfall fields are evaluated in regards to the seasonal cycle and mean monsoon precipitation rate over the validation period 1986-1999. Mean rainfall seasonal cycles shown in Figure 3 for Pandam Eru, Kudaliar and South Gundal locations (referenced in Figure 4) suggest for all GCMs, substantial improvements for downscaled data compared to large-scale outputs. The gain appears to be better for humid (South Gundal) and semi-arid (Kudaliar) regions than for arid areas (Pandam Eru), illustrating the varying performance of the method depending on climatic environments.

The mean JJAS pattern from IMD observed rainfall (Figure 4 upper right panel) shows maximum rainfall rates over the northeastern regions and along the west coast, while minimum values over central southern India separate these two regions. Clearly, such a structure is not found accurately in any of the GCMs used in this study. Nevertheless, these gradients are well reproduced in downscaled rainfall fields for all GCMs. The main differences between downscaled GCMs data are terized by the amplitudes of the above extreme the monsoon season: for instance, greatest maxim ues over northeast India are found for CNRM scaled rainfall while central regions of southern I the least dry for BCCR2 resulting local-scale da

Dry spells lengths PDFs at Pandam Eru, Kud South Gundal locations are shown for original an scaled GCMs together with IMD observation in $\mathrm{F}$ The different climatic conditions over these wa are well represented from observed rainfall with ing slopes from arid to wetter climate. Inflexio within short dry spells lengths suggest that mo dry spells have a duration below five days bu varying proportion over all watersheds, short $\mathrm{d}_{1}$ being less prevalent for arid and semi-arid region $60-70 \%$ ) than for wetter climate (almost $80 \%$ differences are less clear for the original GC. (dashed coloured lines): large biases are found ing both slopes and proportion of short and lor spells. Nevertheless, downscaled fields (thick lines) systematically exhibit a better represent dry spells lengths compared to raw GCMs rai arid (Pandam Eru) and semi-arid (Kudaliar) reg these locations out of the five GCMs dataset, E appears to be the closest to observed dry spells 


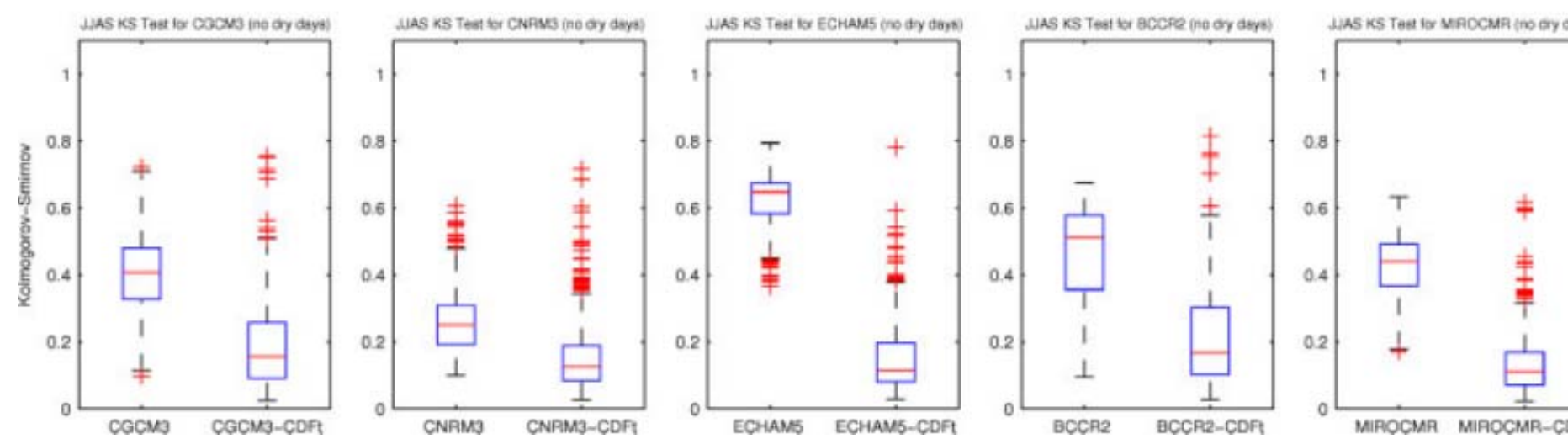

Figure 2. Similar to Figure 1 but after removal of days with no rainfall.

from IMD data, similarly for downscaled fields, downscaled ECHAM5 rainfall provide the best results. The remaining four GCMs display larger biases while substantial gains in dry spells representation characterize their corresponding downscaled rainfall fields. For wetter climatic conditions (South Gundal), similar but less efficient improvements are noticeable between original and downscaled GCMs precipitation except in the case of ECHAM5 for which dry spells lengths PDF from original GCM outputs seems closer to IMD observation than the resulting downscaled data. This could indicate a lesser performance of the CDF-t method for wetter climatic regions in terms of dry spells lengths.

Finally, JJAS anomalies over the 1986-1999 period for original and downscaled GCMs rainfall at the different watersheds (not shown) suggest that interannual variability within the resulting local-scale data is driven by the GCM outputs. Compared to IMD observations, no GCM seems able to reproduce the observed year to year monsoon rainfall variability, and such is the case regarding their corresponding downscaled fields.

\subsection{Surface temperatures}

Regarding annual fields, even though some scores are still above significance level (not plotted), KS statistics shown in Figure 6 (top panels) exhibit systematic improvements for downscaled GCMs surface temperatures when compared to observation. Interestingly, the spatial dispersion of the KS is much smaller for the resulting high resolution fields than for original GCMs data. Concerning the monsoon period, no such gain is found for JJAS KS diagnostics (Figure 6 bottom panels): except from CNRM3, statistical scores are similar to those obtained for original GCMs data.
Mean surface temperatures seasonal cycle at $\mathrm{Pa}$ Eru, Kudaliar and South Gundal locations are pre in Figure 7 for the 1986-1999 period. For all water in dry or more humid conditions, downscaled fiel systematically improved compared to original surface temperatures and are fitting closely the observations over this historical period.

All mean JJAS GCMs downscaled surface ten tures (Figure 8) display patterns close to what is obs for IMD data while fields from original GCMs presenting substantial biases. In particular, the la nal gradient along the west coast which is subj marked discrepancies in large-scale GCM outputs, represented in all downscaled data. The meridiona dient from western to eastern parts of the subcon is also better reproduced in resulting local-scale $\mathrm{s}$ temperatures, with a more or less marked minimun northeastern regions, as found in IMD observation

Mean JJAS surface temperatures differences be the validation (1986-1999) and calibration (1971periods are plotted in Figure 9 for raw GCM outpu IMD observations. Noteworthingly, no much diff is found for IMD observations but also for CNRM while other GCMs are characterized by more o marked variations. Given that CDF-t downscaled are strongly driven by the evolution of the original outputs, this could explain the poor JJAS KS sco Figure 6 for CGCM3, ECHAM5, and BCCR2 res local-scale data.

In addition, JJAS surface temperature anomalies different watersheds locations for the 1986-1999 (not shown) exhibit substantial discrepancies in of interannual variability for raw GCM outputs compared to observations. Here again, these differ remain in the downscaled data. 


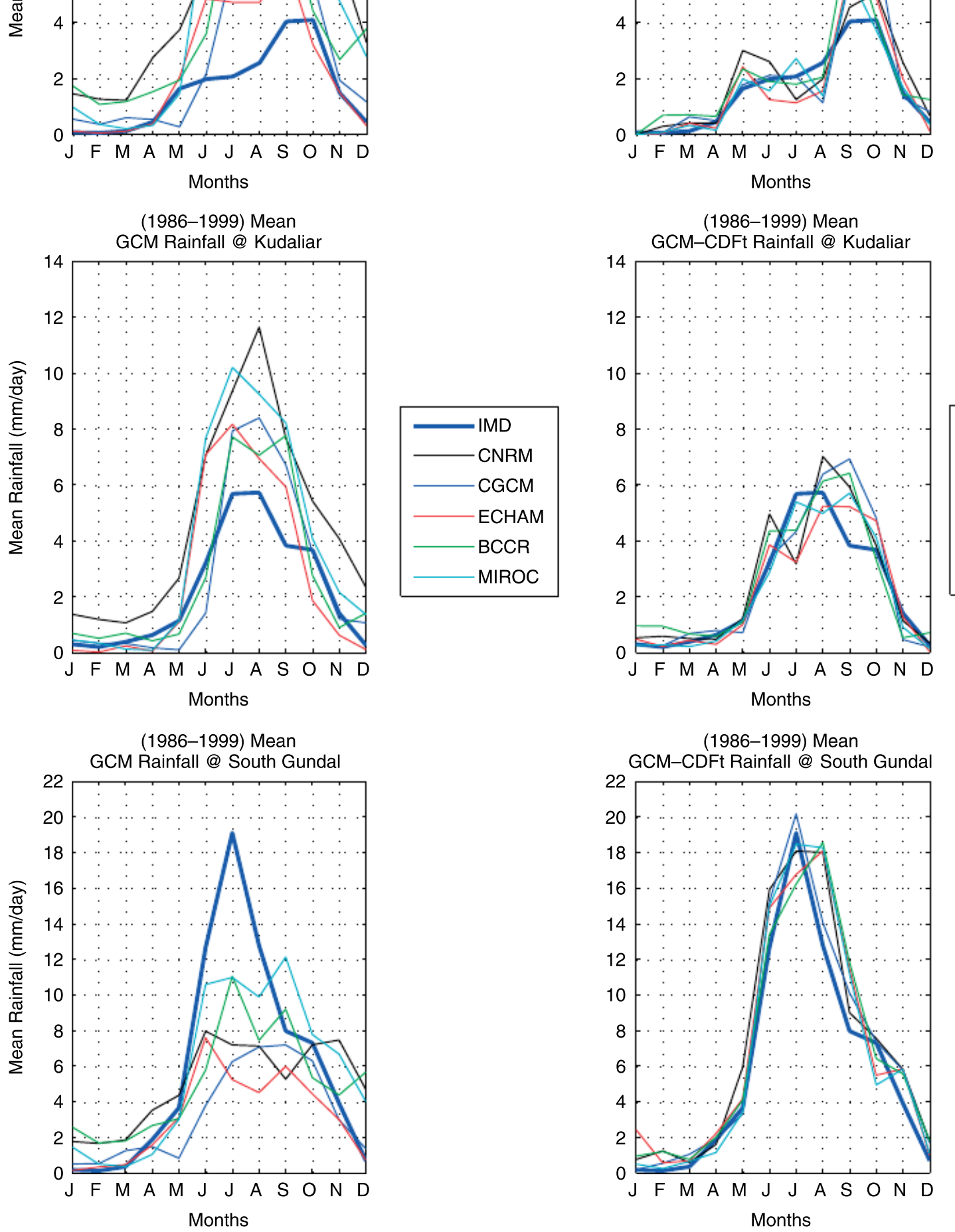

Figure 3. Mean seasonal cycle (in $\mathrm{mm} \mathrm{d}^{-1}$ ) at Pandam Eru (top panel), Kudaliar (middle panel) and South Gundal (bottom panel) lo original (left) and downscaled (right) GCMs rainfall together with IMD observation (thick blue line) over the 1986-1999 period, with of the CDF-t over 1971-1985.

\section{Application to projected GCM A2 scenarios}

The CDF-t method is now applied to downscale largescale precipitation and surface temperature projections from IPCC AR4 experiments under the greenhouse gas emission scenario A2 over southern India. As for the historical period, resulting high resolution fields are generated by applying CDF-t by months GCM outputs. Regarding the availability of daily for the GCMs selected within the PCMDI 2046-2065 (hereafter A2 period) is the period for downscaling future A2 scenarios at mediu The 1971-1999 period is used for calibration t in order to take advantage of the longest $p$ 



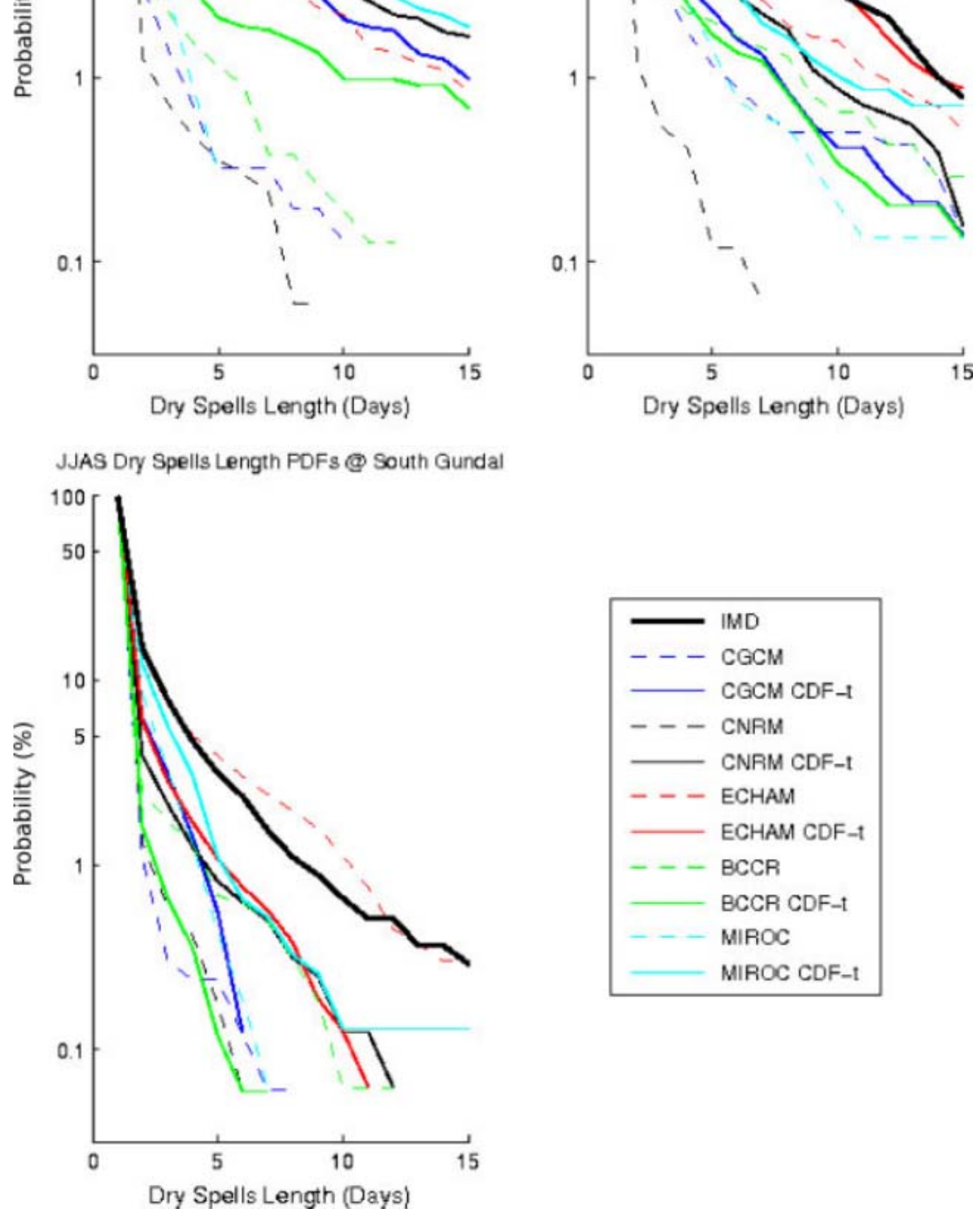

Figure 5. Dry spells length PDFs (in \%) at Pandam Eru (top left), Kudaliar (top right) and South Gundal (bottom) locations for origin coloured lines) and downscaled (thick coloured lines) GCMs data together with IMD observations (black thick line) over the $1986-19$ with calibration of the CDF-t over 1971-1985.

about $80 \%$ of precipitated amounts) respectively while negative variations from January to April are less substantial (maximum about $0.5 \mathrm{~mm} \mathrm{~d}^{-1}$ in March, about $50 \%$ decrease). Overall, these results corroborate findings from previous studies emphasizing enhanced precipitation over southern India, mostly during the monsoon season (Rupa Kumar et al., 2006; Tripathi et al., 2006; Kripalani et al., 2007; Anandhi et al., 2008).

Regarding JJAS rainfall means (Figure 12 two top panels), downscaled fields are more coherent with the known climatology from IMD data for the historical pe Figure 4) than raw GCMs. In particular, maxim cipitated amounts along the west coast and $n$ regions of the subcontinent as well as the cen terns associated to more arid regions, are well rep in the resulting downscaled fields from all GC course, there is no benchmark to compare fut jections, nevertheless these regional variations more realistic for downscaled rainfall than for inal GCM projections. Moreover, the spatial $\mathrm{ch}$ 


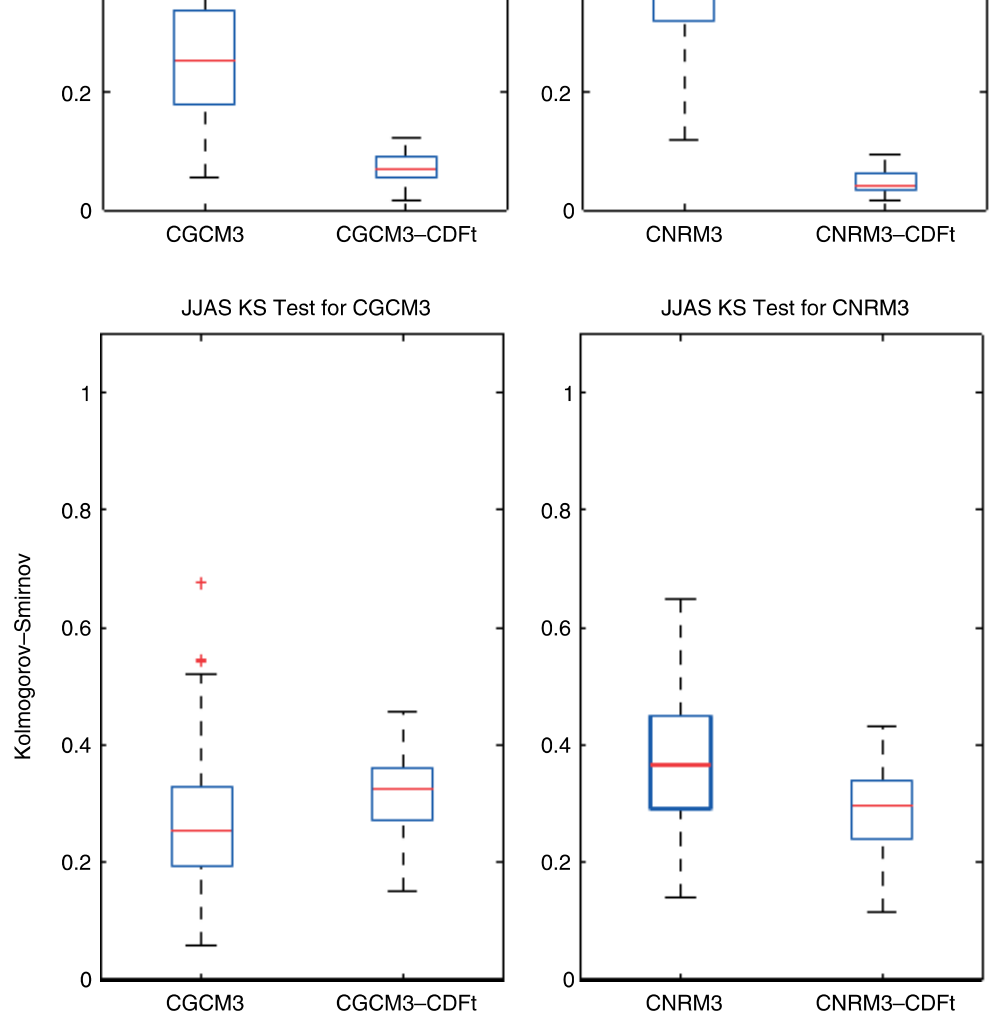
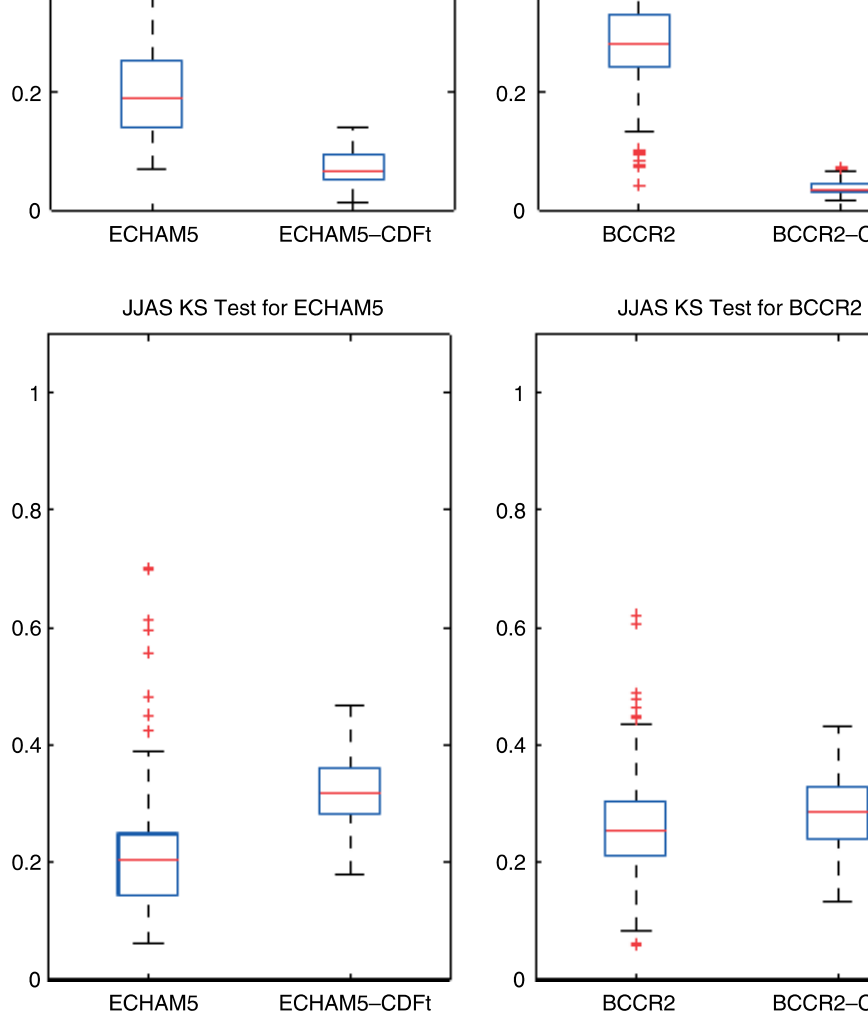

Figure 6. Kolmogorov-Smirnov statistics for original (left box-plots) and downscaled (right box-plots) GCMs surface temperature compared to IMD observation data over the 1986-1999 period for the whole of southern India, with calibration of the CDF-t over 1971 Statistical scores for the full year and the JJAS period are presented in the top and bottom panels, respectively.

JJAS rainfall obtained for individual GCM downscaled data (Figure 12 bottom panels) are systematically comparable to these from their corresponding raw GCM outputs. The amplitudes of these variations however appear to be enhanced for the resulting high resolution fields, corroborating findings from JJAS KS scores (Figure 10), with most pronounced differences over western coastal areas and northeastern regions of the subcontinent.

Differences in dry spells lengths PDFs between the A2 and $\mathrm{XX}$ periods are presented for the three watersheds in Figure 13. At all locations, maximum changes are found for short dry spells lengths (below $5 \mathrm{~d}$ ) with enhanced variations for the downscaled fields when compared to raw GCM outputs. At Pandam Eru and Kudaliar, the mean GCM A2 projections in JJAS are characterized by a reduction of very short dry spells (below $2 \mathrm{~d}$ ), while dry spells with a duration above $2 \mathrm{~d}$ are likely to increase. The reverse is found for the wetter South Gundal basin with enhanced very short dry spells occurrences and a reduction of longer periods without rain (above two days) during the monsoon season. Interestingly similar results are found from mean raw GCM projections at Kudaliar and South Gundal locations with some differences in terms of magnitude of these changes. However, original
GCMs data would rather suggest a slight incre very short dry spells at Pandam Eru contrasting wi reduction suggested by the resulting high resolution

\subsection{Projected surface temperatures}

Surface temperature variations associated with rainfall regime changes are examined here in order $t$ further description of A2 scenario projections cons in this study. As mentioned in Section 2.1, due availability of daily surface temperatures data $f$ 2046-2065 period, only four GCMs will be u this part (MIROCMR daily surface temperatures unavailable from PCMDI archives at the time o study).

Similarly to Figure 10, KS diagnostics charac surface temperatures evolution for both the full a cycle and the monsoon season for all GCMs (Figur As shown by their respective median, a signal similar amplitude is recovered from the origina downscaled GCMs data between the contemporary and the projected A2 scenario, downscaled median being a little lower than for raw GCMs exce ECHAM5. A slightly higher spatial dispersion is for CGCM3, ECHAM5 and BCCR2 downscaled 


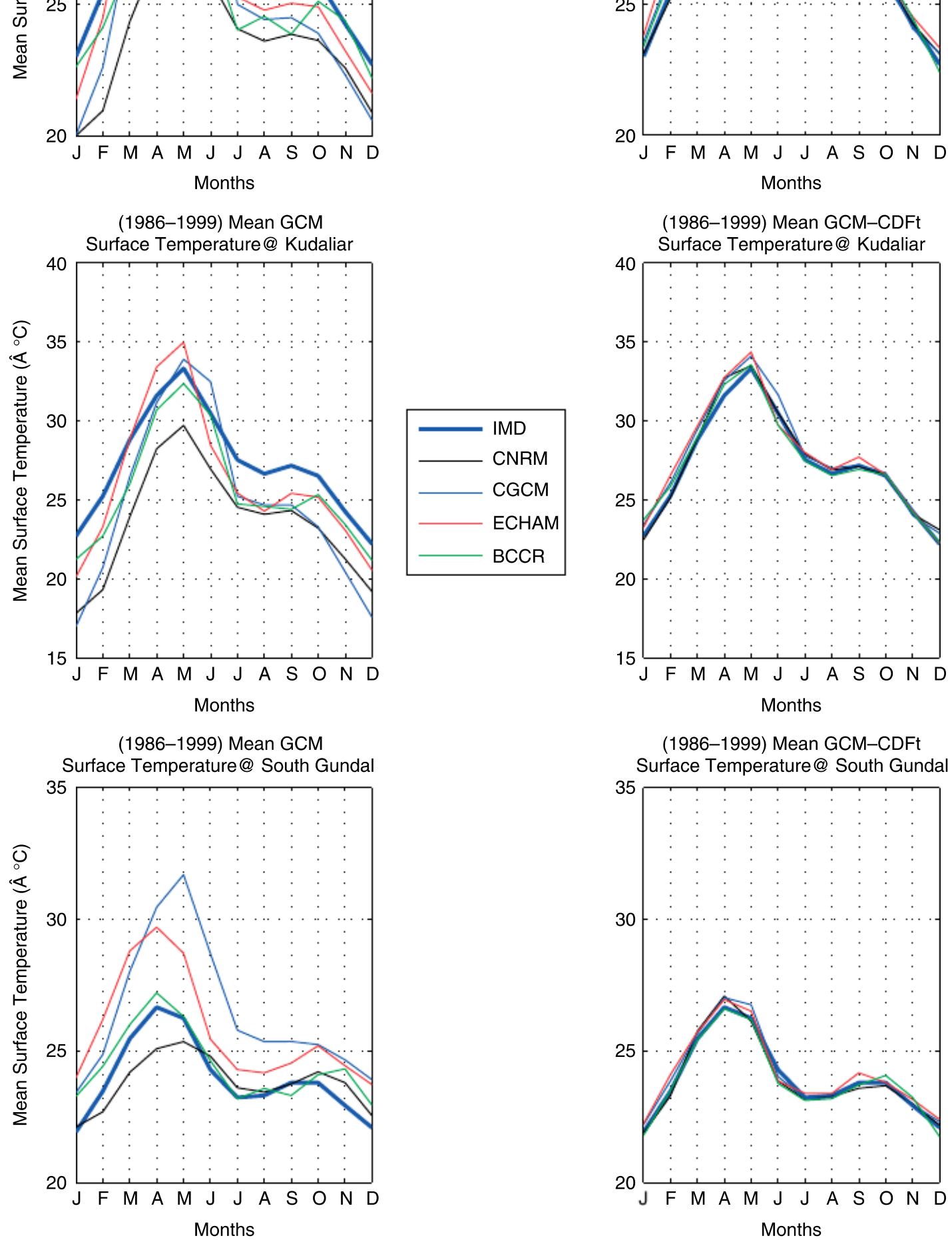

Figure 7. Mean seasonal cycle (in ${ }^{\circ} \mathrm{C}$ ) at Pandam Eru (top panels), Kudaliar (middle panels) and South Gundal (bottom panels) lo original (left) and downscaled (right) GCMs surface temperatures together with IMD observation (thick blue line) over the $1986-19$ with calibration of the CDF-t over 1971-1985.

compared to GCM outputs, but overall the KS scores are roughly of the same order for both the full year and the monsoon season. Such results would suggest very similar evolutions between the A2 and XX periods for large-scale GCMs and downscaled surface temperatures.

Mean surface temperatures seasonal differences from the $\mathrm{XX}$ to the $\mathrm{A} 2$ periods with the CDF-t method are compared in Figure 15 with raw GCMs. Bot $\mathrm{t}$ downscaled fields and raw GCMs data lead similar conclusions in terms of GCMs ensembl at least. Despite the dispersion within all GCM tions, GCMs ensemble mean surface temperature appear to be more pronounced over arid an arid basins (Pandam Eru and Kudaliar respective 



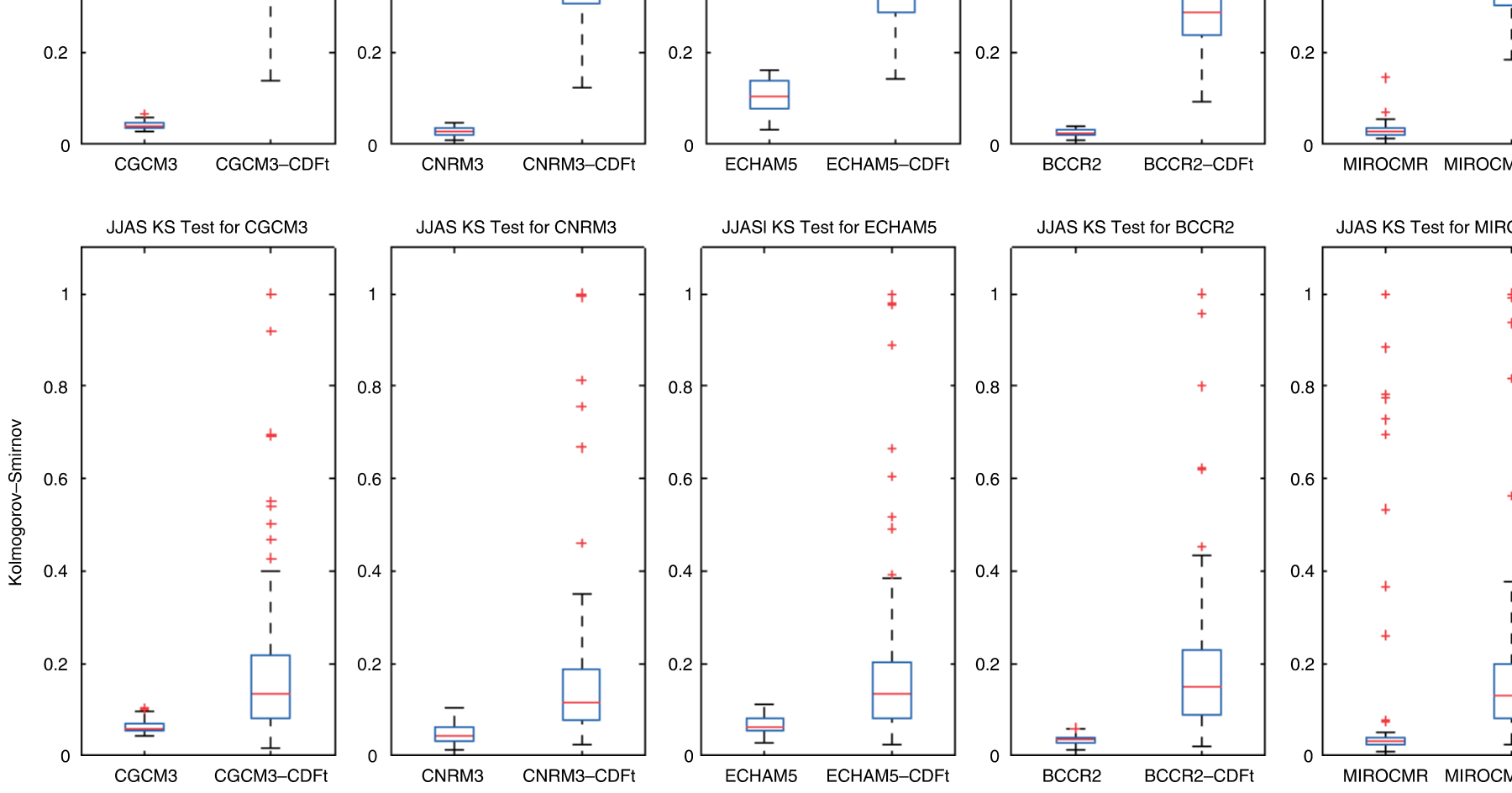

Figure 10. Kolmogorov-Smirnov statistics between original (left box-plots) and downscaled (right box-plots) GCMs rainfall for the A (2046-2065) and the 1971-1999 calibration period for the whole of southern India. Scores for the full year and the JJAS period are in the top and bottom panels, respectively.

\section{Discussion and conclusions}

In order to downscale GCM projections over southern India for the whole annual cycle, the CDF-t method (Michelangeli et al., 2009) has been applied to monthly chronicles of daily large-scale rainfall and surface temperatures. First, CDF-t has been validated on the 1986-1999 period and compared to historical IMD observations. In terms of KS statistics, resulting localscale fields exhibit substantial improvements in comparison to original GCM outputs regarding distribution characteristics but also mean seasonal cycle and monsoon means for both precipitation and surface temperatures. Then, the CDF-t method has been applied to GCMs climate simulations of the 21st century under the SRES A2 scenario. Resulting high resolution fields have been compared to original GCM outputs at different locations (arid, semi-arid and wetter environment) where both lead to similar conclusions. Concerning precipitation, the results show a substantial increase of rainfall in particular during the monsoon season and for semi-arid and wetter climatic zones (from about 15 to 50\%) while winter precipitation are generally reduced (maximum decrease of about $50-80 \%$ for wetter climatic regions) in accordance with previous findings (Rupa Kumar et al., 2006; Kripalani et al., 2007; Raje and Mujumdar, 2009). These changes are accompanied by increases in surface temp most pronounced during the post-monsoon (up to and winter season at all locations also agreei earlier studies (Rupa Kumar et al., 2006; Bhatt 2007).

This method was used to provide local-scale variables for impact studies (hydrological an economical) at basin scale over southern India, stressed region where the impacts of global cha due to increase significantly (Kundzewicz et al. Most statistical downscaling studies generally $f$ a single season (for example JJAS) and dov projections from different GCMs for the full rarely documented. The monthly approach cho gave better results than for the full year (not and supports findings from other studies regar need to seasonalize SDMs for better projected lo estimates (Tripathi et al., 2006).

The same non-parametric approach was chose study to downscale separately rainfall and surf: peratures. However, in the case of rainfall, the cipitation' occurrences (which are particularly ir during the dry season) may need more develc Days without precipitation are generally not ad represented in GCM outputs, and this could at 



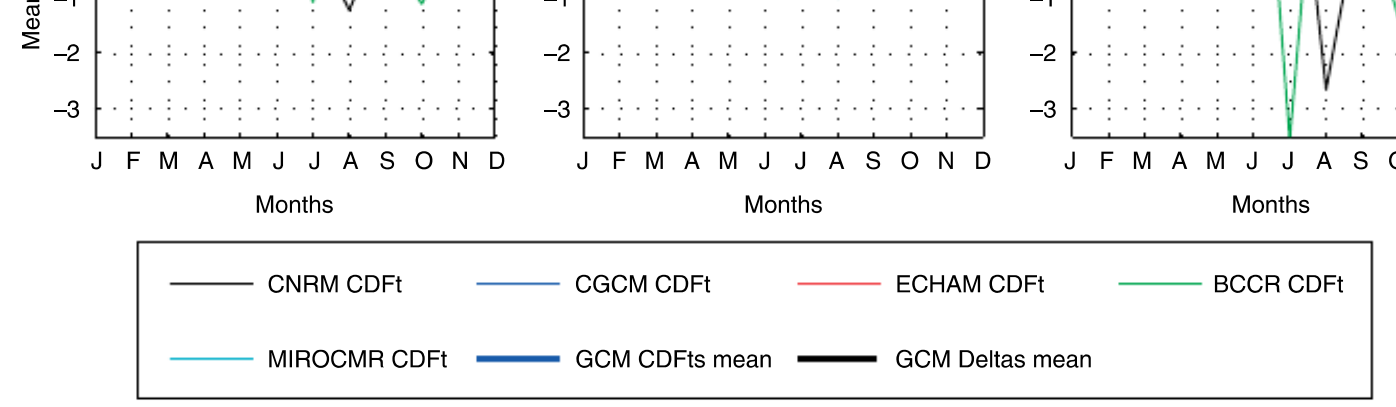

Figure 11. Mean seasonal rainfall cycle changes (in $\mathrm{mm} \mathrm{d}^{-1}$ ) at Pandam Eru (left panel), Kudaliar (middle panel) and South Gundal (righ locations between the A2 (2046-2065) and XX (1980-1999) periods seen by CDF-t compared to results from raw GCMs output
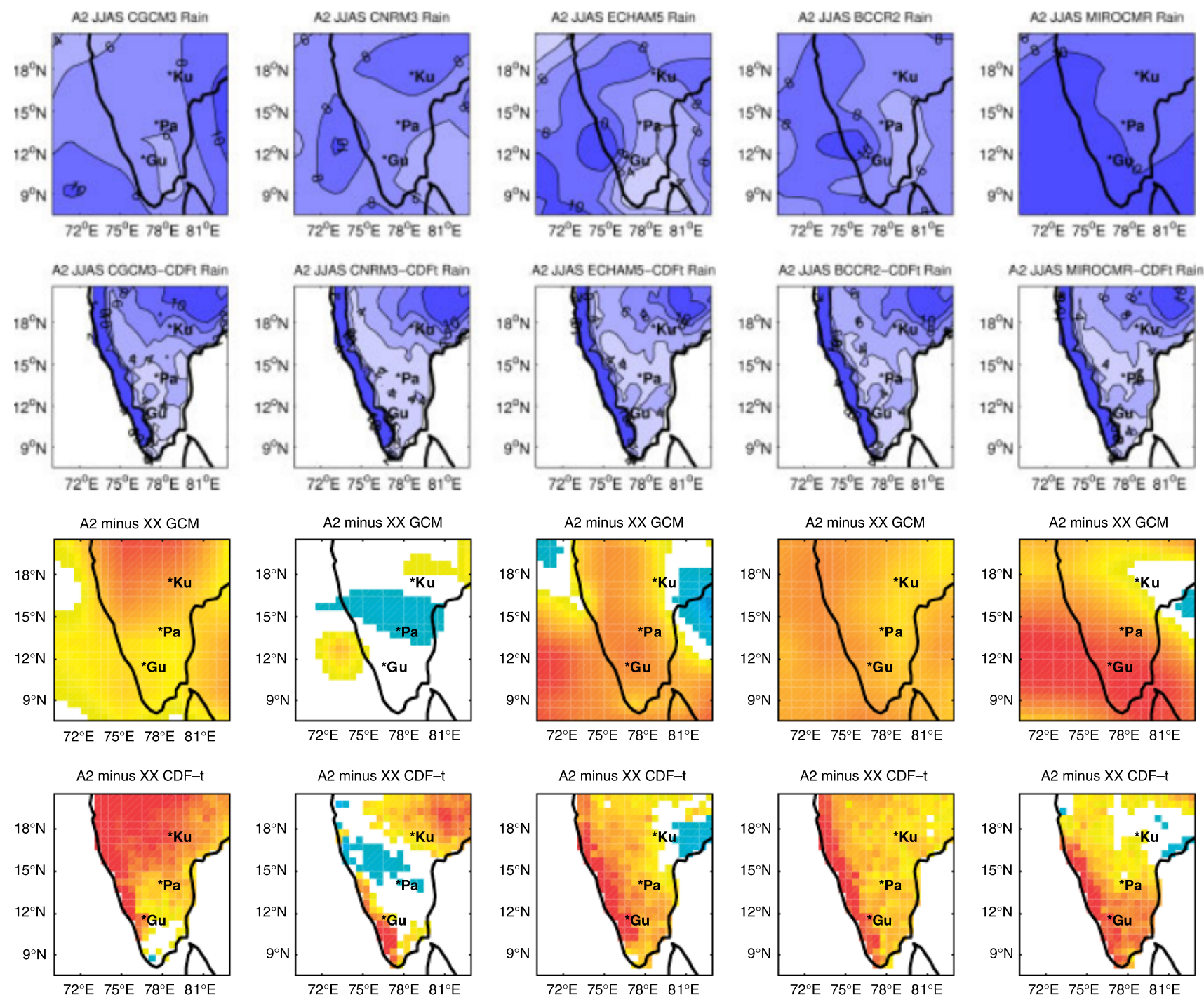

Figure 12. Mean June to September original (top panels) and downscaled (second line) GCMs rainfall for the A2 scenario (2046-206 southern India as well as the original GCMs (third line) and CDF-t projected (bottom panels) changes (in $\mathrm{mm} \mathrm{d}^{-1}$ ) when comparec historical XX period (1980-1999).

CDF-t formulation used for downscaling rainfall. As shown in Section 3.1, dry days are better represented in downscaled precipitation than in GCMs data when compared to observation. Nevertheless, for all GCMs
CDF-t seems to perform better, in terms of dry day precipitated amount, during the monsoon season wi 'no-precipitation' occurrences, than for the whole To address this issue, a next step would be to use 



However, this paper corresponds to one more step in that direction helping to document medium-range future climatic scenarios (2040-2060), these horizons being crucial for local adaptation strategies.

\section{Acknowledgements}

This study has been supported by the Agence Nationale pour la Recherche (ANR) through the VMCS program (project SHIVA contract ANR-08-VULN-010-01) and the Bureau de Recherches Géologiques et Minières (BRGM). The authors thank the SHIVA partners for their contribution. Mathieu Vrac was partially funded by the GIS-REGYNA Project. IMD observations were obtained from the Institute of Meteorology Department of India. GCM outputs from the IPCC AR4 exercise were downloaded from the PCMDI server (http://www.pcmdi.llnl.gov/ipcc/model_documentation/). The downscaling has been realized with the 'CDF$t$ ' $R$ package freely available on the CRAN website (http://cran.r-project.org/).

\section{References}

Anandhi A, Srivanas V, Kumar DN, Nanjundiah RS. 2009. Role of predictors in downscaling surface temperature to river basin for IPCC SRES scenarios using support vector machine. International Journal of Climatology 29: 583-603.

Anandhi A, Srivanas V, Nanjundiah RS, Kumar DN. 2008. Downscaling precipitation to river basin in India for IPCC SRES scenarios using support vector machine. International Journal of Climatology 28: $401-420$.

Bhattacharya S. 2007. Lessons learnt for vulnerability and adaptation assessment from India's first national communication, vol 7, BASIC EU Project.

Cruz R, Harasawa M, Wu S, Anokhin Y, Punsalmaa B, Honda Y, Jafari M, Li C, Ninh NH. 2007. Asia Climate Change 2007: Impacts, Adaptation and Vulnerability. Contribution of Working Group II to the Fourth Assessment. Cambridge University Press: UK, 469-506.

Darling D. 1957. The Kolmogorov-Smirnov, Cramer-von Mises tests. Annals of Mathematical Statistics 28: 823-838.

Flato GM, Boer GJ, Lee WG, McFarlane NA, Ramsden D, Reader MC, Weaver AJ. 2000. The Canadian Centre for Climate Modeling and Analysis of Global Coupled Model and its climate, Climate Dynamics 16: $451-467$.

Furevik T, Bentsen M, Drange H, Kindem IKT, Kvamsto NG, Sorteberg A. 2003. Description and evaluation of the Bergen Climate Model: ARPEGE coupled with MICOM, Climate Dynamics 21: 27-51.

Ghosh S, Mujumdar P. 2007. Nonparametric methods for modelling GCM scenario uncertainty in drought assessment. Water Research 43: W07405, 19 pp., DOI: 10.1029/2006WR005351.

Ghosh S, Mujumdar P. 2008. Statistical downscaling of GCM
Kundzewicz Z, Mata L, Arnell N, D'll P, Kabat P, Miller K, Oki T, Sen Z, Shiklomanov I. 2007. Freshwater and their Management. Cambridge University Press: UK, Michelangeli P, Vrac M, Loukos H. 2009. Probabilistic ing approaches: application to wind cumulative distribu tions. Geophysical Research Letters 36: L11708, 6 10.1029/2009GL038401.

Mujumdar P, Ghosh S. 2008. Modelling GCM and scena tainties using a possibilistic approach: application to the River. Water Resources Research 44: W06407, 15 pp., DO 2007WR006137.

Nakicenovic N, Davidson O, Davis G, Grbler A, Kram " ELL, Metz B, Morita T, Pepper W, Pitcher H, Sankovski P, Swart R, Watson R, Dadi Z (eds). 2000. In Special Emissions Scenarios: A Special Report of Working Group Intergovernmental Panel on Climate Change. Cambridge Press: 599.

Paeth H, Scholten A, Friederichs P, Hense A. 2008. Un in climate change prediction: El Nino-Southern Oscil monsoons. Global and Planetary Change 60: 265-288.

Prudhomme C, Reynard N, Crooks S. 2002. Downscaling climate models for flood frequency analysis: where are Hydrological Processes 16: 1137-1150.

Raje D, Mujumdar P. 2009. A conditional field-based do method for assessment of climate change impact on mul precipitation in the Mahanadi basin. Water Resources Re W10404, 20 pp., DOI: 10.1029/2008WR007487.

Rajeevan M, Bhate J. 2008. A high resolution gridded rainf (1971-2005) for mesoscale meteorological studies. vo Research Report.

Rupa Kumar K, Sahai A, Kumar KK, Patwardhan S, Revadekar J, Kamala K, Pant G. 2006. High-resolutio change scenarios for India for the 21st century. Curre 90(3): 334-345.

Salas-Melia D, Chauvin F, Deque M, Douville H, Gu Marquet P, Planton S, Royer JF, Tyteca S. 2006. Descr validation of the CNRM-CM3 global coupled mode Dynamics (in press).

Srivastava A, Rajeevan M, Kshirsagar S. 2008. Developmen resolution daily gridded temperature dataset (1969-200 Indian region. vol 8, NCC Research Report.

Tripathi S, Srinivas V, Nanjundiah SR. 2006. Downs precipitation for climate change scenarios: a support vect approach. Journal of Hydrology 330: 621-640.

Vrac M, Naveau P. 2007. Stochastic downscaling of precipita dry events to heavy rainfalls. Water Resources Research 43 13 pp., DOI: 10.1029/2006WR005308.

Vrac M, Stein M, Hayhoe K. 2007. Statistical downs precipitation through non-homogeneous stochastic weath Climate Research 34: 169-184, DOI: 10.3354/cr00696.

Wilby R, Charles S, Zorita E, Timbal B, Whetton P, Mearn Guidelines for use of climate scenarios developed from downscaling methods. Supporting Material of the IPCC,

Wilks D, Wilby R. 1999. The weather generation game: of stochastic weather model. Progress in Physical Geog 329-357.

Wood A, Sridhar V, Lettenmaier D. 2004. Hydrologic impli dynamical and statistical approaches to downscaling clim outputs. Climate Change 62: 189-216. 
